\title{
A Study on Motivation Mechanism for Target Attainment of Energy Conservation and Emission Reduction Program in Xinjiang Province
}

\author{
Zhang $\mathrm{Na}$ \\ Commercial College \\ Shihezi University \\ Wujiaqu, China \\ zhangnanuaa@163.com
}

\author{
Liu Xiaqing \\ College of Foreign Studies \\ Shandong Institute of Business and Technology \\ Yantai, China \\ liuxiaqing111@163.com
}

\begin{abstract}
This paper studied a motivation mechanism for attaining the target of energy conservation and emission reduction program in Xinjiang Province, China. It is known that the final goal of enterprises and governments is to realize profit maximization, based on which this paper set up a complete and imperfect information dynamic game model with enterprises and governments as two parties involved. Through the analysis of the model, it was found that reducing governments' inspection cost cannot urge enterprises to conduct the conservation and emission reduction program and intensifying punishment for illegality behaviors which are against the energy conservation and emission reduction program will promote the development of enterprises' energy conservation and emission reduction program.
\end{abstract}

Keywords-energy conservation and emission reduction; motivation mechanism; influencing factor; government punishment; Xinjiang

\section{INTRODUCTION}

"Pigovian tax" or "Pigovian fee" is levied to restrain enterprises' environment pollution behaviors abroad, which provides basic frameworks for governments to participate in ecological environmental management in the form of enforcing mandatory institutions ${ }^{[1-4]}$. Chinese scholars built principal-agent models and excitation functions for linear payment contracts, solved the models by means of government utility original value maximization method, got the optimal government fixed subsidy and motivation intensity factors, and finally proposed countermeasures for promoting enterprises' energy conservation and emission reduction development $^{[5]}$. This paper studied a motivation mechanism for energy conservation and emission reduction program in Xinjiang province, China, from the perspective of game theory ${ }^{[6-10]}$, aiming to motivate the enterprises to take immediate actions into the program and provided references for the realization of the program target.

\section{ANALYSIS ON ENERGY SAVING AND}

\section{EMISSION REDUCTION STATUS IN XINJIANG}

\section{PROVINCE}

During the 12th Five-Year Plan period, energy consumption per GDP is 2.013 ton standard coal per for a million CNY in Xinjiang area in 2011, which rises by about 4.52 percent compared with 2010. Emissions for chemical oxygen demand (cod), sulfur dioxide (So2), ammonia nitrogen, and nitric oxide rises by 127 percent, 29.67 percent, 75.94 percent and 28.42 percent respectively compared with 2010. Energy consumption per GDP and main pollution emissions increase on a yearon-year basis. The situation is grim now. From 2005 to 2010 , energy consumption per GDP showed a weakening trend, but it rose sharply in 2010 and 2011 (see table 1). In the respect of decreasing rate or increasing rate in the table 1, its index first dropped dramatically and increased rapidly from 2007, which illustrates that there are problems in energy saving and emission reduction implementation before the 12 th $\underline{\text { Five-Year Plan. }}$

TABLE I ENERGY CONSUMPTION PER GDP FROM 2005 TO 2011 IN XINJIANG AREA

\begin{tabular}{|c|c|c|c|c|c|c|c|}
\hline Year & $\mathbf{2 0 0 5}$ & $\mathbf{2 0 0 6}$ & $\mathbf{2 0 0 7}$ & $\mathbf{2 0 0 8}$ & $\mathbf{2 0 0 9}$ & $\mathbf{2 0 1 0}$ & $\mathbf{2 0 1 1}$ \\
\hline $\begin{array}{c}\text { energy consumption per GDP (ton standard coal/ ten thousand } \\
\text { Yuan) }\end{array}$ & 2.11 & 2.092 & 2.027 & 1.963 & 1.934 & 1.926 & 2.013 \\
\hline $\begin{array}{c}\text { increasing rate or decreasing rate }(\%) \\
\text { \%) }\end{array}$ & & -0.853 & -3.11 & -3.16 & -1.48 & -0.41 & 4.52 \\
\hline
\end{tabular}

Note: GDP is calculated by constant price in 2005 .

Data source: Xinjiang Statistical Yearbook 2006-2013, China Statistical Yearbook 2006-2013.

From 2005 to 2010 , energy consumption per GDP in cities in Xinjiang province emerged an uptrend at different levels. Thereinto, the city with the largest ascensional range is Turpan area, where energy 
consumption per GDP increased from 1.17 ton standard coal per ten thousand Yuan in 2005 to 3.2 ton in 2010. There is an energy consumption disequilibrium among different areas, for example, the energy consumption of Shihezi city is 77 times more than that of Ili Kazakh Autonomous Prefecture. The disequilibrium has corresponding relations with the status of economy development. For instance, the top four for energy consumption are those highly-developed Urumqi Municipality, Shihezi City, Karamay City, and Bortala Mongol Autonomous Prefecture. The cities with less energy consumption are Yilihashake Autonomous Prefecture, Kizilsu Kirghiz Autonomous Prefecture, Kashi Prefecture and Hotan Prefecture.

TABLE II ENERGY CONSUMPTION PER GDP FOR CITIES IN XINJIANG AREA UNIT: TON STANDARD COAL / TEN THOUSAND YUAN

\begin{tabular}{|c|c|c|c|c|c|c|}
\hline & 2005 & 2006 & 2007 & 2008 & 2009 & 2010 \\
\hline $\begin{array}{c}\text { Urumqi } \\
\text { Municipality }\end{array}$ & 3.64 & 3.50 & 3.30 & 3.23 & 3.14 & 3.19 \\
\hline Karamy City & 4.92 & 4.41 & 4.06 & 3.97 & 4.33 & 4.66 \\
\hline Shihezi City & 3.59 & 4.10 & 4.63 & 5.78 & 6.79 & 6.94 \\
\hline Turpan Area & 1.17 & 1.28 & 1.62 & 1.99 & 2.15 & 3.20 \\
\hline $\begin{array}{c}\text { Hami } \\
\text { Prefecture }\end{array}$ & 1.91 & 2.01 & 1.87 & 1.74 & 2.11 & 2.11 \\
\hline $\begin{array}{c}\text { Hui } \\
\text { Autonomous } \\
\text { Prefecture of } \\
\text { Changji } \\
\end{array}$ & 1.46 & 1.46 & 1.56 & 1.86 & 2.19 & 2.59 \\
\hline $\begin{array}{c}\text { Yilihashake } \\
\text { Autonomous } \\
\text { Prefecture }\end{array}$ & 0.08 & 0.05 & 0.06 & 0.07 & 0.08 & 0.09 \\
\hline $\begin{array}{c}\text { Bortala } \\
\text { Municipality }\end{array}$ & 5.42 & 6.31 & 6.38 & 6.09 & 6.47 & 8.00 \\
\hline $\begin{array}{c}\text { Bayingolin } \\
\text { Mongol } \\
\text { Autonomous } \\
\text { Prefecture } \\
\end{array}$ & 1.24 & 1.30 & 1.19 & 1.27 & 1.27 & 1.39 \\
\hline $\begin{array}{c}\text { Akesu } \\
\text { Prefecture }\end{array}$ & 2.57 & 2.90 & 3.10 & 2.69 & 2.85 & 2.98 \\
\hline $\begin{array}{c}\text { Kizilsu } \\
\text { Kirghiz } \\
\text { Autonomous } \\
\text { Prefecture } \\
\end{array}$ & 0.36 & 0.50 & 0.06 & 0.08 & 0.12 & 0.50 \\
\hline $\begin{array}{c}\text { Kashi } \\
\text { Prefecture }\end{array}$ & 0.40 & 0.40 & 0.52 & 0.51 & 0.51 & 0.41 \\
\hline $\begin{array}{c}\text { Hotan } \\
\text { Preference }\end{array}$ & 0.26 & 0.26 & 0.32 & 0.27 & 0.28 & 0.29 \\
\hline
\end{tabular}

Note: GDP is calculated by constant price in 2005 .

Data source: Xinjiang Statistical Yearbook 2006-2013.

\section{CONSTRUCTION OF MIXED STRATEGY NASH EQUILIBRIUM}

As long as an enterprise has other options, it will not conduct energy conservation and emission reduction program from rational thinking. However, in reality, enterprises should not only consider their own operation state, but the effects of the program as well. On one hand, enterprises try their best to dodge the program; on the other hand, governments try their best to guarantee the uttermost implementation of the program by means of inspection and punishment.

The profit maximization for governments and enterprises are opposite, so the two parties have formed a non-cooperation game. The game model is as follows. The pure strategies for enterprises are pollution abatement or non-abatement, while the pure strategies for governments are inspection or non-inspection. Hereby, we assumed that enterprises could get the payoff $T$ no matter which strategy it took, and would be punished with penalty once governments discovered their environmental pollution behaviors. Given the cost of pollution abatement $C_{1}$, the penalty multiple $a$ which satisfies $a=[0.5,5]$, the inspection cost $C_{2}$, then there are $T>C_{1}$ and $a T>C_{2}$ . The payoffs matrix is expressed in table 3 .

TABLE III PAYOFF MATRIX OF ENTERPRISES AND GOVERNMENTS FOR ENERGY CONSERVATION AND EMISSION REDUCTION PROGRAM

\begin{tabular}{|c|c|c|c|}
\hline \multicolumn{2}{|c|}{} & \multicolumn{2}{|c|}{ governments } \\
\cline { 2 - 4 } \multicolumn{2}{|c|}{ enterprises } & inspection & non-inspection \\
\hline & \begin{tabular}{c} 
abatement \\
\cline { 2 - 4 }
\end{tabular} & $T-C_{1},-T-C_{1}$ & $T-C_{1},-T$ \\
\hline & abatement & $-a T,-a T-C_{2}$ & $T,-T$ \\
\hline
\end{tabular}

From table 3, we can get that when governments choose inspection strategy, the optimal strategy for enterprises is pollution abatement; when enterprises choose abatement, the optimal strategy for governments is non-inspection; when enterprises choose non-abatement, government had better implement inspection. Thus there is no pure strategy Nash equilibrium. Nevertheless, governments and enterprises can choose mixed strategies with probability involved, which in turn constitutes mixed strategy Nash equilibrium.

Suppose the non-abatement probability for enterprises is $P$, and inspection probability for governments is $Q$, then the expected payoffs for $P=1$ and $P=0$ can be expressed as below respectively.

(1)

$$
E P(1, Q)=(-a T) Q+T(1-Q)=T-(1+a T) Q
$$

$$
E P(0, Q)=\left(T-C_{1}\right) Q+\left(T-C_{1}\right)(1-Q)=T-C_{1}
$$

According to payoff equivalence method, given $E P(1, Q)=E P 0, Q)$, thus marginal probability for governments inspection is $Q^{*}=C_{1} /(T+a T)$. If $Q<Q^{*}$, enterprises will choose non-abatement; if $Q \geq Q^{*}$, enterprises will choose abatement instead. The expected payoffs for inspection $P=1$ and non-inspection $P=0$ are expressed as below respectively.

$$
\begin{aligned}
& E Q(P, 1)=\left(a T-C_{2}\right) P+\left(-T-C_{2}\right)(1-P) \\
& =-C_{2}+(T+a T) P \\
& E Q(P, 0)=(-T) P+(-T)(1-P)=-T
\end{aligned}
$$

According to payoff equivalence method, given $E Q(P(1)=E Q P, 0)$, thus marginal probability for enterprises non-abatement is $P^{*}=C_{2} /(T+a T)$. If $P<P^{*}$, the optimal strategy for governments is noninspection; if $P<P^{*}$, governments will get the maximum payoff through inspection.

From the above game model, we get the mixed strategy Nash equilibrium is $P=C_{2} /(T+a T)$, and 
$Q=C_{1} /(T+a T)$. That is to say, enterprises carry out pollution abatement with the probability $C_{2} /(T+a T)$, and governments implement inspection with the probability $C_{1} /(T+a T)$. Another explanation is that there are $C_{2} /(T+a T)$ enterprises choose non-abatement strategy, and the rest $1-C_{2} /(T+a T)$ enterprises will conduct pollution abatement. Governments can not inspect all the enterprises in view of human and finance cost and will choose $C_{1} /(T+a T)$ enterprises as samples for their inspection.

\section{ASYMMETRIC INFORMATION GAME EQUILIBRIUM MODEL FOR ENTERPRISES AND GOVERNMENTS}

The information asymmetry between enterprises and governments exist. First of all, governments, as lawmakers and executers for energy conservation and emission reduction program, know rules and relevant regulations for the program better than enterprises.
Furthermore, enterprises are unable to get all the pollution abatement information. On account of limited human resources for governments in Xinjiang province and incomplete information network, enterprises have information superiority over governments in their own pollution abatement behaviors. The institution for the program realization also has drawbacks. Enterprises file declaration and harness pollution voluntarily, and government inspect later, which bring up a lot of opportunists who do not declare their pollution actions.

To sum up, enterprises and governments make up two game parties for an incomplete information game. Harsanyi proposed a method bringing in a psedo-player, namely nature, to process the incomplete information game. The options of nature are used to describe the random factors in the game, which converts an incomplete information static game into a complete and imperfect information dynamic game. The dynamic game is an extension for the above-mentioned static game model, in which the probability for legality of enterprises affirmed by governments is $R$, and a game tree is formed as below Fig. 1.

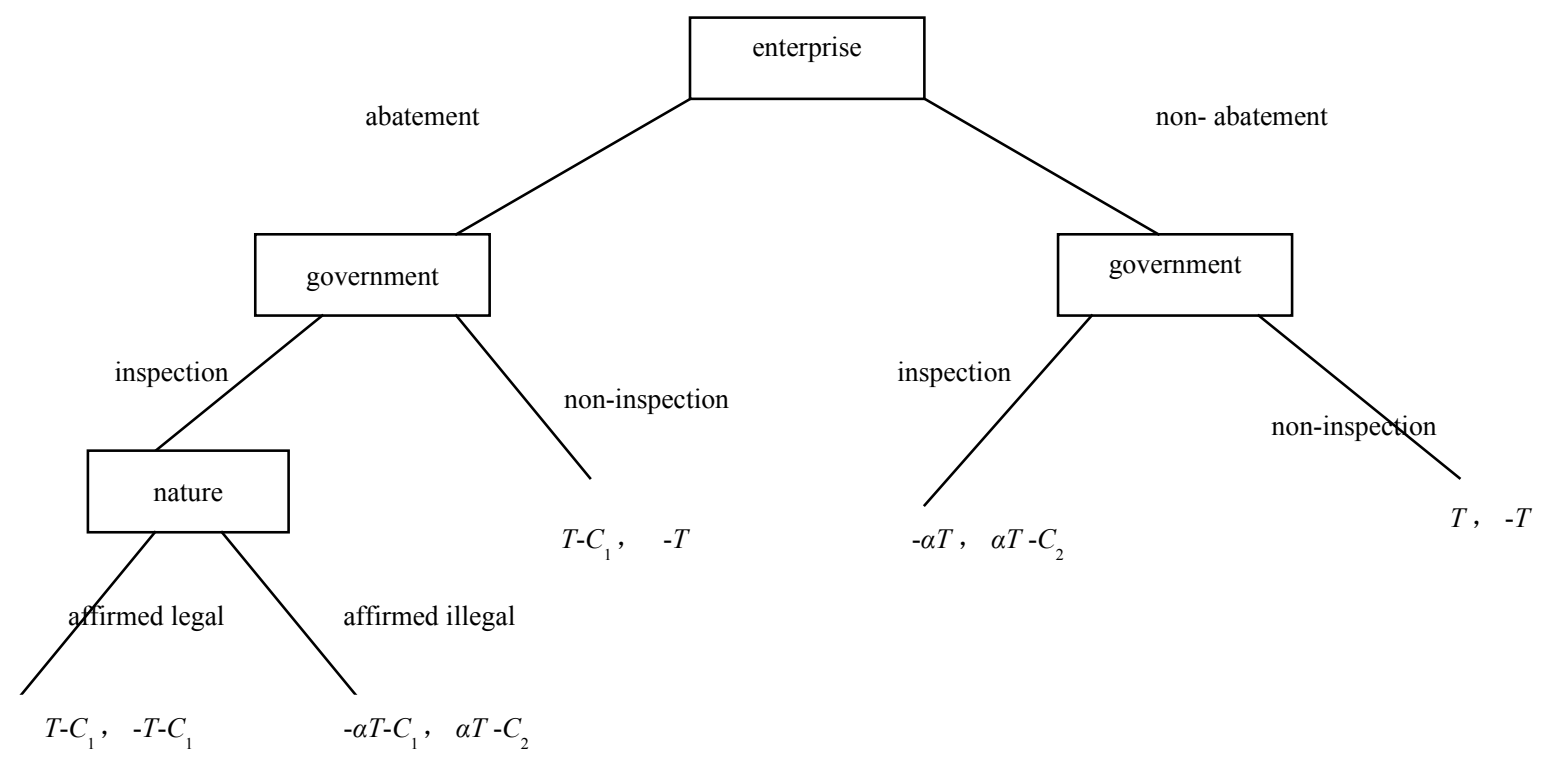

Figure 1. a dynamic game tree for energy conservation and emission reduction program implementation

\section{A. If Enterprises Adopt Pollution Abatement}

Strictly speaking, implementing energy conservation and emission reduction program is a legal behavior which conforms to the lawmakers' intent, but this legality should be approved by governments, in the process of which governments may have law enforcement deviation, that is to say, even if enterprises adopt pollution abatement, government may identify as non-abatement or pseudoabatement and punish the enterprises, given the penalty $a T$. From the foregoing game tree model, we can get enterprises' expected payoff under the circumstance of government inspection is

$$
\begin{aligned}
& E_{1}=\left(T-C_{1}\right) R+\left(-a T-C_{1}\right)(1-R) \\
& =-a T-C_{1}+(T+a T) R
\end{aligned}
$$

If $E_{1} \geq 0$, namely, $R \geq\left(a T+C_{1}\right) /(T+a T)$, payoff enterprises got from the energy conservation and emission reduction program is much more than that from nonabatement. If $E_{1}<0$, namely, $R<\left(a T+C_{1}\right) /(T+a T)$, enterprises will choose non-abatement. Under the circumstance of governments non-inspection, the expected payoff for enterprises is $E_{2}=T-C_{1}$. By this time, enterprises will obviously choose pollution abatement. Combing the probability of government inspection and legality affirmation, the expected payoff for enterprises when they are unsure about inspection implementation is as below.

$$
\begin{aligned}
& E_{3}=\left[\left(T-C_{1}\right) R+\left(-a T-C_{1}\right)(1-R)\right] Q+\left(T-C_{1}\right)(1-Q) \\
& =(-T-a T)(1-R) Q+T-C_{1}
\end{aligned}
$$

Assume that enterprises are willing to conduct energy conservation and emission reduction program, then 
$E_{3} \geq 0$, and thus $Q(1-R) \leq\left(T-C_{1}\right) /(T+a T)$. In this case, enterprises have economic motivation for pollution abatement when government implement inspection and the probability of illegality affirmation for enterprises' abatement behavior is less than $\left(T-C_{1}\right) /(T+a T)$.

It can be concluded that if probability for governments' legality affirmation satisfies $R \geq\left(a T+C_{1}\right) /(T+a T)$, and only if the inspection probability and affirmation probability satisfies $Q(1-R) \leq\left(T-C_{1}\right) /(T+a T)$, enterprises will conduct energy conservation and emission reduction program.

\section{B. If Enterprises Adopt Non-abatement}

When enterprises do not conduct pollution abatement, enterprises will be identified as illegality if government inspect, and they will be penalized for $a T$. The expected payoff for enterprises' non-abatement is gotten from the game tree as

$$
E_{4}=(-a T) Q+T(1-Q)=T-(T+a T) Q
$$

If $E_{4} \geq 0$, that is, governments' inspection probability satisfies $Q \leq T /(T+a T)$, enterprises will have the economic motivation for non-abatement. Whereas, enterprises may choose pollution abatement as well, because it also depends on enterprises' willingness for obeying laws and their value to a large extent. If $E_{4}<0$, that is, governments' inspection probability satisfies $Q>T /(T+a T)$, which shows that enterprises' nonabatement has no economic value, a rational enterprise will not choose pollution abatement. Of course, there are exceptions. If enterprises and governments have rentseeking relationship, the choices of enterprises still depend on the relationship between rent-seeking cost $C X$ and penalty expense $a T$.

If $C X \geq a T$, enterprises will choose non-abatement, for the reason that non-abatement behavior is uneconomical even on the condition of rent-seeking. If $C X<a T$, there is non-abatement motivation as long as enterprises conduct rent-seeking activities with governments. Thus, it is vital to strengthen governments' legal system conciseness, intensify punishment for rentseeking activities between governments and enterprises, and encourage and develop enterprises' planning for energy conservation and emission reduction program.

\section{SUGGESTIONS FOR MOTIVATION MECHANISM CONSTRUCTION}

It is suggested to adopt the following measures which are gotten from the motivation mechanism game model.

Firstly, increase inspection cost to facilitate enterprises conduct energy conservation and emission reduction program. From $P^{*}=C_{2} /(T+a T)$, we can get the probability for enterprises' non-abatement $P$ is in direct proposition to governments' inspection cost $C_{2}$. That is, the higher the inspection cost, the more enterprises to adopt non-abatement, and vice versa. With the cost reduction for inspection, the probability for enterprises' non-abatement is beyond governments' expectation, then governments are inclined to inspect. As for enterprises, they are apt to choose non-abatement to avoid penalty. Therefore, it is inadvisable to increase inspection cost and conduct large-scale tax examination, which will in turn worsen the situation. It is recommended that governments conduct spot check on typical enterprises and reduce inspection cost actively, in order to refrain enterprises non-abatement activities and promote the development of the program.

Secondly, high cost for non-abatement hinders enterprises' pollution non-abatement. Form $Q^{*}=C_{1} /(T+a T) \quad$ we can get probability for governments' inspection $Q$ is in direct proposition to enterprises' non-abatement cost $C_{1}$. That is, the higher the non-abatement cost, the more often governments inspect. Meanwhile, increasing inspection cost $C_{2}$ will hinder enterprises' non-abatement. In order to avoid energy conservation and emission reduction, enterprises have to collect a great deal of information including their own information and information of pollution abatement rules and regulars, which makes enterprises forecast changing tendency of external environment.

Thirdly, to intensify punishment, strengthen supervision, improve inspectors' quality can promote the development of the program. From $P^{*}=C_{2} /(T+a T)$ and $Q^{*}=C_{1} /(T+a T)$, we can get that $P$ and $Q$ are inversely proportional to the penalty multiple $a$. It is also gotten from conclusion 2 and 3 that the larger $a$, the smaller $P$ and $Q$. At present, the energy conservation and emission reduction mechanism is deficient, a sound supervisory mechanism has not been set up, and some inspectors have low quality, which result in the fact that some enterprises form rent-seeking relationship by means of seeking favors or bribing inspectors, which in turn lead to the development of non-abatement and hinder the development of the program. Therefore, it is critical to strengthen governments' supervisory mechanism and improve inspectors' quality.

\section{ACKNOWLEDGMENT}

This paper is sponsored by the National Natural Science Foundation of China (No. 71171113, No. 71363046, No.71301064); the Humanistic and Social Science Foundation of Ministry of Education of China (No. 10YJA790174); the Humanistic and Social Science Youth Foundation of Ministry of Education of China (No. 13YJC790198).

\section{REFERENCES}

[1] Alain-Desire Nimubona, B Sinclair-Desgagné. The Pigouvian Tax Rule in the Presence of an Eco-industry[Z]. 2005.

[2] Canton, J. Environmental Taxation and International EcoIndustries, Nota de lavoro[Z]. 2007.

[3] Alain-Desire. Nimubona Pollution Policy and Liberalization of Trade in Environmental Goods[Z]. 2010.

[4] Arthur Cecil Pigou. Welfare Economics[M]. Shanghai University of Finance and Economics press, 2009.

[5] Xue Fen, Zheng Chuiyong. Study on Long-term Mechanism for Government to Encourage Enterprises on Energysaving\&Emission Reduction Considering Enterprises' Emotion Factor[J]. Social Sciences in Nanjing, 2012(03): 36-40.

[6] Ru-yin Long, Lan Yu.Study on regulation design about energysaving and emission-reduction based on game theory[J]. Procedia Earth and Planetary Science.2009(1).

[7] Huang Xin, Tao Xiaoma, Du Zenghua. Game analysis on control policies of energy conservationand emission reduction[J]. Journal of Guangxi University, 2008, 33(3): 322-326. 
[8] Koski C. Examining state environmental regulatory policy design[M]. Routledge. 2007: 483-502.

[9] $\mathrm{Yu}$ Xiaojun. Evolutionary Game Analysis on Energy-Saving and Emission Reduction[J]. Ecological Economy, 2011(4): 50-53.

[10] Maynard S J. Evolution and the theory of games [M]. Cambridge
University Press, 1982. 